\title{
Effects of Initial Pore Diameter on the Oil Absorption Behavior of Potato Chips during Frying Process
}

\author{
Jinwei Li, Tingting Zhang, Yuanfa Liu and Liuping Fan* \\ State Key Laboratory of Food Science and Technology, School of Food Science and Technology, Jiangnan University, Wuxi 214122, CHINA
}

\begin{abstract}
How initial pore diameter in materials affects oil absorption has been rarely studied up to now. Herein, we provided direct data evidence suggesting that the pore diameter prior to frying closely related to the oil absorption behavior. The pore had no significant effect on oil absorption of potato chips $(p>0.05)$ when its diameter was 0.1 and $0.2 \mathrm{~mm}$ compared with the control. However, the oil absorption increased with the increasing of pore diameter when it was $0.3-1.2 \mathrm{~mm}$. The oil absorption tended to be saturated at $0.9 \mathrm{~mm}$ pore diameter. In addition, we analyzed the moisture content, total oil (TO), surface oil (SO), penetrated surface oil (PSO) and structural oil (STO) contents of potato chips. The results when using palm oil showed that there was no significant difference in moisture, TO and STO contents of samples with pore diameter of 0.1 and $0.2 \mathrm{~mm}$ during the whole frying processing respectively compared with the control $(p>$ 0.05). When pore diameter was $0.3-1.2 \mathrm{~mm}$, STO and TO contents significantly increased with the rising of the diameter $(p<0.05)$. The SO content and PSO content dropped as increasing in frying time for the samples with different pore diameters. The equilibrium TO content of samples with $0.3-0.9 \mathrm{~mm}$ pore significantly increased with the rising of pore diameter, which was about $6.2-22.5 \%$ higher than that of the control. And there was no significant difference in the equilibrium TO contents of both samples of $1.2 \mathrm{~mm}$ and $0.9 \mathrm{~mm}$ pore $(p>0.05)$. STO fraction gave the greatest contribution to the increment of oil absorption.
\end{abstract}

Key words: pore diameter, oil absorption, structural oil content, total oil content, puncture

\section{Introduction}

Frying is a complex and important operation immersing food into hot oil at temperature above the boiling point of water, typically within a range from 150 to $200^{\circ} \mathrm{C}^{1)}$. The fried foods are always irresistible for us because of their peculiar organoleptic properties such as good mouth-feel, distinct flavor, unique taste and palatability ${ }^{2)}$.

As it is known, the high fat and calories of fried food could increase the risk of obesity, hypertension, cardiovascular diseases, diabetes and cancers ${ }^{3)}$. Therefore, lots of researchers used different methods, including pre-drying treatment, to reduce the oil content of the fried food. Troncoso and Pedreschi ${ }^{4)}$ fried air-dried potato slices and reported oil absorption diminished by $30 \%$. Moreira et al..$^{5}$ fried baked tortillas and found lower final oil content. Krokida et $a l .{ }^{6)}$ observed that osmotic dehydration pretreatment led to the decrease of final oil content. Zielinska et $a{ }^{7)}{ }^{7)}$ claimed that superheated steam drying resulted in potato chips with $15-27 \%$ lower fat content compared to the chips without treated. Most of them insisted that the decrease of the initial moisture content of materials was attributed to the reduction of oil absorption. Whereas, Moreno and Bouchon ${ }^{8)}$ reported that freeze-drying increased oil suction of fried potato chips compared with the control, mainly because of the porous structure that reduces the resistance to oil absorption. It indicated that pore in food matrix had a marked effect on oil absorption ${ }^{9-12)}$. On the other hand, different pre-drying methods created the pore with different characters, which may be responsible for the reduction or rising of oil uptake.

Pore parameters mainly included macroscopic and microscopic index. The most important macroscopic pore parameters are density, porosity, specific surface area and breakthrough capillary pressure ${ }^{13)}$. Microscopic pore structure parameters are pore size (diameter, volume), pore size distribution and the volume distribution function ${ }^{14)}$. Pinthus et al. ${ }^{15)}$ evaluated the effects of initial porosity of a restructured potato product by exposing the samples to

\footnotetext{
*Correspondence to: Liuping Fan, State Key Laboratory of Food Science and Technology, School of Food Science and Technology, Jiangnan University, Wuxi 214122, CHINA

E-mail: fanliuping@jiangnan.edu.cn

Accepted February 15, 2016 (received for review November 21, 2015)
}

Journal of Oleo Science ISSN 1345-8957 print / ISSN 1347-3352 online

http://www.jstage.jst.go.jp/browse/jos/ http://mc.manusriptcentral.com/jjocs 


\section{J. Li, T. Zhang and Y. Liu et al.}

various periods at fluctuating subfreezing temperatures on oil uptake and observed that the higher initial porosity increased oil uptake. Cortes et al. ${ }^{16)}$ developed glass micromodels, which were built with the same pore size distribution but different radii of pore throats, to get direct evidence of oil transport phenomena. Until now, the effects of pore size of materials on oil absorption have not been reported. While, pore size significantly affected the diffusion properties $^{17-20)}$. Based on these, we attempted to exploit the effect of pore size on oil absorption of fried samples.

The operation of pre-drying and simulation system may lead to irregularity, uncontrollable and broad range of pore size and the gradient of connectivity, which were complicated in the interpretation of the dynamics of oil uptake and increased the difficulty of study ${ }^{21)}$. Based on this, the puncture experiment with different pore diameters was used to obtain uniform and controllable pores in fresh potato slices and the effect of initial pore diameter on oil absorption was investigated. The dyed oil method ${ }^{9)}$ was used to identify the oil distribution. The moisture content, TO, SO, STO and PSO contents of the potato chips with different diameters pores during frying process were investigated and analyzed. This study may remind manufacturer that the structure (pore size) formed by pre-drying can be taken into consideration for producing the fried food with lower fat. And it laid the groundwork for developing the current methods and exploiting new methods of reducing the oil content in food industry.

\section{Materials and methods}

\subsection{Materials}

Potato (Solanum tuberosum) of variety Favorita used in this study were purchased from a local market in Wuxi, China. Palm oil (Jiali Co. Ltd., Shanghai, China) was used as frying media. Sudan I (SCRC chemical) was dyed oil to dis- tinguish different oil fractions.

\subsection{Sample preparation}

The potato tubers were sorted, washed, peeled, and cut into slices (thickness of $3 \mathrm{~mm}$, diameter of $22 \mathrm{~mm}$ ). Slices were rinsed in distilled water for $1 \mathrm{~min}$ to eliminate some starch adhering to the surface. All slices were blanched by heating in boiling water for $3 \mathrm{~min}$, and the ratio of potato to water was 1:8(w/w). Then excess surface water was removed by blotting on absorbent paper. The potato slices were uniformly punctured 30 pores with the same diameter of 0 (control) $0.1,0.2,0.3,0.6,0.9$ or $1.2 \mathrm{~mm}$ for the further frying experiments. As shown in Fig. 1A, the megascopic pore could only be found when the pore diameter is more than $0.9 \mathrm{~mm}$.

\subsection{Frying experiments}

\subsubsection{Oil dyed with Sudan I preparation}

A heat resistant dyed oil was prepared by dissolving 10.2 $\mathrm{g}$ of the oil soluble and heat resistant stain Sudan I SCRC chemical, China) in $1 \mathrm{~L}$ of the frying oil.

\subsubsection{Frying process}

Frying was carried out in a beaker containing $400 \mathrm{~mL}$ palm oil, which was put into the electric-heated thermostatic oil bath at $180 \pm 2{ }^{\circ} \mathrm{C}$ (Jingda Equipment Manufacturer, Jintan, China). The palm oil was preheated for $2 \mathrm{~h}$ before frying. Fresh potato slices were fried at $180^{\circ} \mathrm{C}$ for 2-12 min. Twenty seconds before the end of frying, $25 \mathrm{~mL}$ of dyed indicator oil solution with the same temperature was added over the next $10 \mathrm{~s}$ and two oils were stirred at the last $10 \mathrm{~s}$. Samples were removed from the beaker and allowed to drain for $10 \mathrm{~min}$ at ambient temperature so that excessive oil was drained off.

\subsection{Determination of moisture content}

Moisture content of fried samples was measured by drying the samples in a vacuum oven(DZF-6050, Jinghong

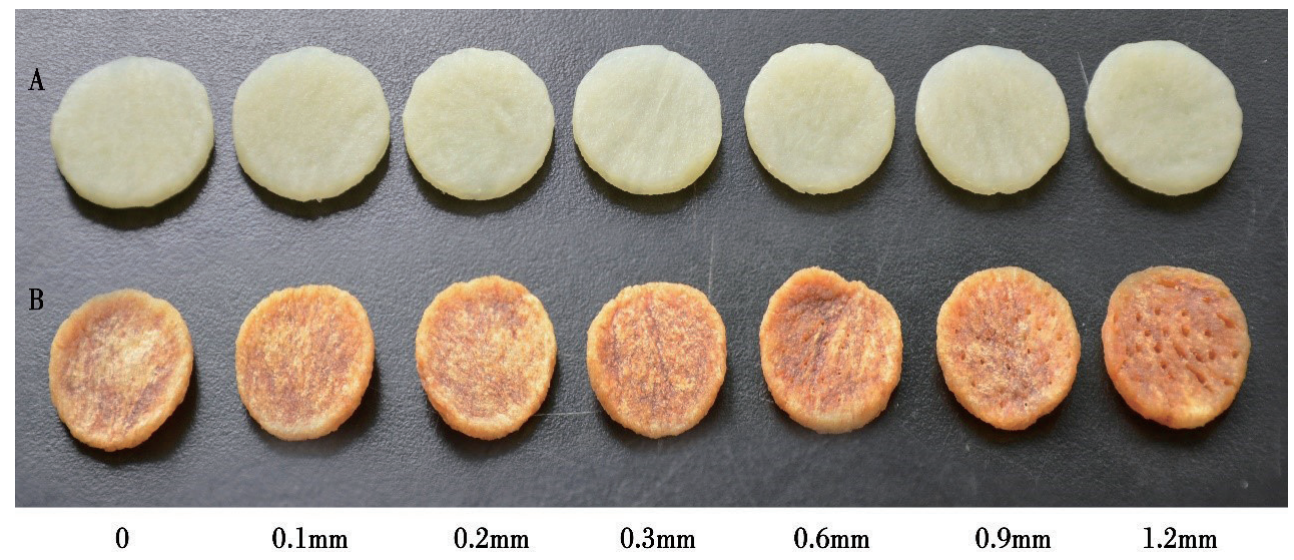

Fig. 1 Photographs of punctured potato chips with different diameter before and after frying (A means before frying and B means after frying). 
Experimental Equipment Co., Shanghai, China) until constant weight was arrived.

\subsection{Determination of oil content}

The total oil content (TO) is divided into three parts: (1) surface oil (SO), which is the oil that remains on the surface, (2) penetrated surface oil (PSO), which represents the oil suctioned into the food during cooling after removal from the fryer, and (3) structural oil (STO), which represents the oil penetrated into the potato microstructure during frying. TO (\%) was determined by the Soxhlet method. Oil fraction contents of SO, PSO and STO were determined by the method of Bouchon et al..$^{9)}$ with a little revision in oil dye and absorbance wavelength.

2.5.1 Calibration curve to determine Sudan I concentration in the frying oil

In the experiment, Sudan I instead of Sudan Red B was used as oil dye. $500 \mathrm{mg} / \mathrm{L}$ Sudan I was prepared and diluted to $4,6,8,10,12,14$ and $16 \mathrm{mg} / \mathrm{L}$ with petroleum ether (boiling range: $30-60^{\circ} \mathrm{C}, \mathrm{SCRC}$, China). The absorbance was measured at $460 \mathrm{~nm}$ (maximum absorbance of Sudan I) by means of a spectrophotometer(UV2600, Shanghai Tianmei Scientific Instrument Co., Ltd, China). A linear plot was obtained between the concentration of the dyed oil and the calibration curve was $\mathrm{y}=46.82 \mathrm{x}+0.03\left(\mathrm{R}^{2}=\right.$ $0.998)$.

2.5.2 Surface oil (SO) content

SO was determined by immersing $5 \mathrm{~g}$ potato chips in 50 $\mathrm{mL}$ of petroleum ether for $1 \mathrm{~s}$ at ambient temperature and calculated after being dried to constant mass in a convective oven (GZX-9140MBE, Boxun Industrial Co., Ltd., Shanghai, China).

2.5.3 Penetrated surface oil(PSO) and structural oil (STO) contents

After SO extraction, potato chips were finely cut and dried to constant mass. Soxhlet extraction was carried out at $70^{\circ} \mathrm{C}$ for $4 \mathrm{~h}$ and the solvent was evaporated at $90^{\circ} \mathrm{C}$ for 30 min using the oil tester (SOX406, Haineng Instrument Co., Ltd., Jinan, China). The soxhlet extracted oil was dried to constant mass in a convective oven at $105^{\circ} \mathrm{C}$. For analysis, soxhlet extracted oil was diluted 50 times with petroleum ether and the absorbance was measured at $459.6 \mathrm{~nm}$. The amount of dyed (PSO) oil was calculated using Eq. (1) below.

$$
\begin{aligned}
\operatorname{PSO}(\%)= & \frac{(\mathrm{TO}-\mathrm{SO}) \times \text { Dye concentrat ion in extracted oil }(\mathrm{mg} / \mathrm{L})}{\text { Dye concentrat ion in oil bath }(\mathrm{mg} / \mathrm{L})} \\
& \times 100 \%
\end{aligned}
$$

The amount of non-dyed oil(STO) was calculated as follows:

$$
\mathrm{STO}(\%)=\mathrm{TO}-\mathrm{SO}-\mathrm{PSO}
$$

\subsection{Analysis of the ratio of increasing of STO content to increasing of TO}

The ratio of increasing of STO content to increasing of TO content was calculated as follows:

$$
\operatorname{Ratio}(\%)=\frac{\mathrm{STO}_{\mathrm{d}}-\mathrm{STO}_{0}}{\mathrm{TO}_{\mathrm{d}}-\mathrm{TO}_{0}}
$$

where $\mathrm{STO}_{\mathrm{d}}$ and $\mathrm{TO}_{\mathrm{d}}$ are respectively STO content and TO content of the samples with pores of different diameter, $\mathrm{STO}_{0}$ and $\mathrm{TO}_{0}$ are respectively STO content and TO content of the control.

\subsection{Statistical analysis}

All experiments were carried out in triplicate. Data analysis was carried out using analysis of variance (ANOVA) with SPSS software version 17.0 for Windows (SPSS 17.0, IBM, Chicago, IL, USA). Significant difference among the mean values was calculated using one-way analysis of variance with the application of Duncan's tests. Mean values were considered significantly different for $p \leq 0.05$.

\section{Results and discussions}

\subsection{Moisture content during frying processing}

After frying, the megascopic pore of potato chips could be obviously found when pore diameter was $0.3-1.2 \mathrm{~mm}$, especially for the chips with pore diameter of $0.6,0.9$ and $1.2 \mathrm{~mm}$, which may be related to the water evaporation. However, just like the control, we could not find the obvious pore for the potato chips with pore diameter of 0.1 and $0.2 \mathrm{~mm}$, which may be related to the gelatinization and swelling of the starch (Fig. 1B).

The moisture contents of fried potato chips with different pore diameters at different time are shown in Fig. 2. For all samples with different pore diameters, there was a sharp decrease of moisture content during the first $6 \mathrm{~min}$ frying; the moisture content exhibited a slow decline from 6 to $10 \mathrm{~min}$; during the last $2 \mathrm{~min}$, there was almost no obvious change in moisture content and the final moisture content were all about $1.5 \%$. The frying time significantly affected the moisture content of fried potato chips for all pore diameters $(p<0.05)$. The similar trend was observed by Krokida et $a l .{ }^{22)}$ and Fan et $a l .^{23)}$ for deep-fat fried French fries and vacuum fried carrot chips respectively. Compared with the control, there was no significant difference in moisture contents of sample with pore diameter of 0.1 and $0.2 \mathrm{~mm}$ during the whole frying processing $(p>$ 0.05). However, the moisture content of the samples with pore diameter of 0.3 to $1.2 \mathrm{~mm}$ showed a trend of decreasing with the increasing of pore diameter at the same frying time. When pore diameter of sample was more than 0.3 $\mathrm{mm}$, it indicated that water evaporation obviously accelerated as the samples with the larger pore diameters were used. 


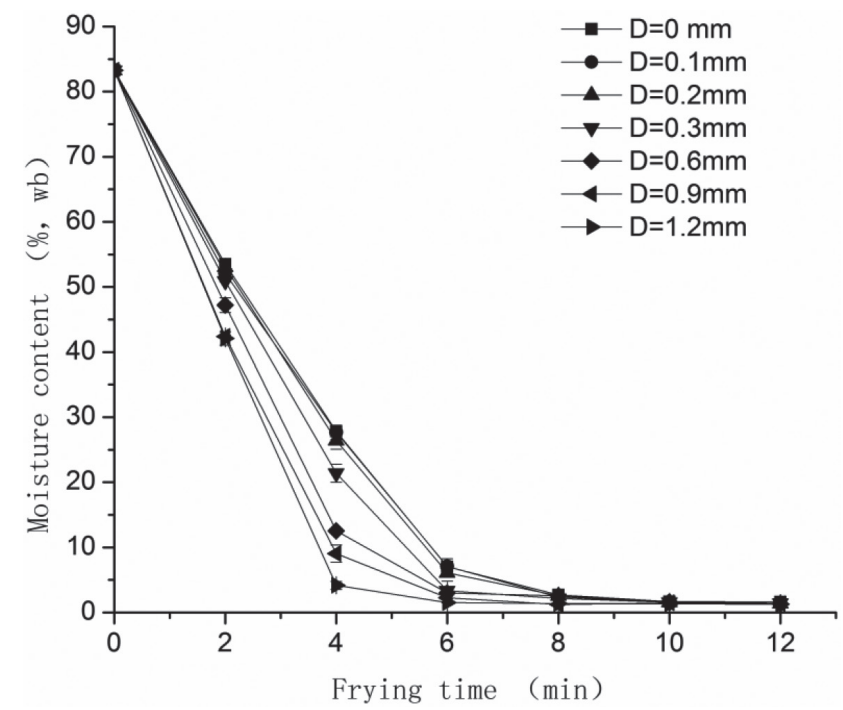

Fig. 2 Moisture contents of fried potato chips with different pore diameters at different frying times.

\subsection{TO content during frying processing}

As shown in Fig. 3, for all samples with different pore diameters, the TO contents all increased to above $40 \%$ at 2 min frying; the TO content of sample with $1.2 \mathrm{~mm}$ pore was up to $60.0 \%$ at 12 min frying. The TO contents of all samples with the different pore diameters significantly increased with the increasing of frying time during the first 8 or $10 \mathrm{~min}(p<0.05)$. In the later frying process $(10-12$ min), all TO contents tended to be constant.

It was shown from Fig. 3 that TO content had no significant difference when pore diameter was 0.1 and $0.2 \mathrm{~mm}$ compared with the control $(p>0.05)$. When the fresh

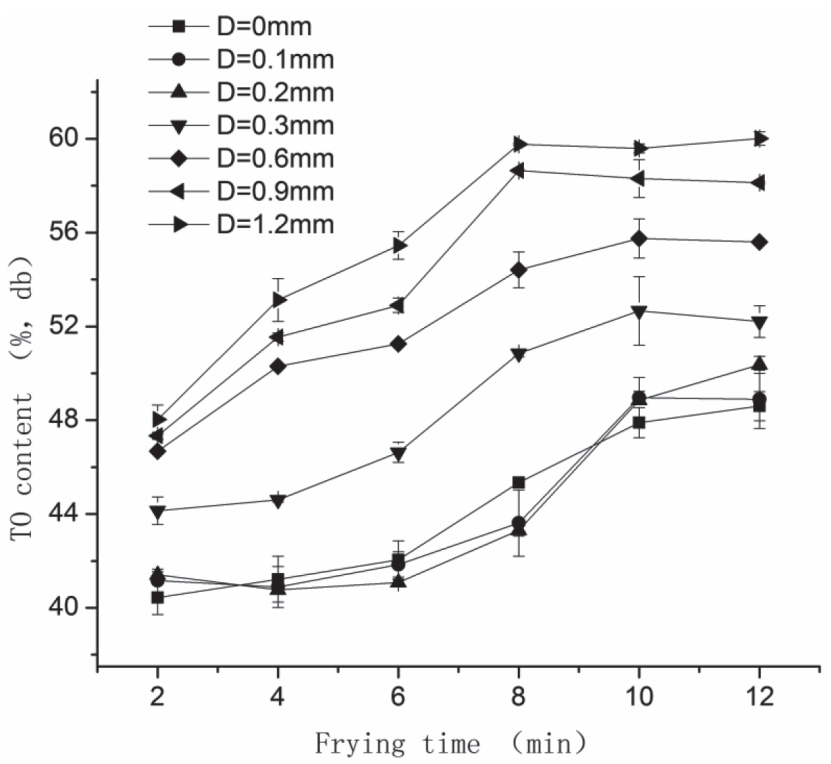

Fig. 3 TO contents of fried potato chips with different pore diameters at different frying times. potato chips were fried in hot oil, granules went through the gelatinization process and caused swelling of the starch beams, which lead to a decrease in pore size ${ }^{24)}$, even the formation of a close-knit matrix ${ }^{18)}$. So the mobility of water was restricted in the corresponding potato chips during frying process, which attributed to the similar properties as the control. When pore diameter was 0.3-1.2 mm, the significant increase in TO content for every pore diameter appeared compared with the control $(p<0.05)$. Tajner-Czopek et $a l .{ }^{25)}$ observed that the pore diameter of French fries obtained by convective pre-dried was about $400 \mu \mathrm{m}$, which was greater than that of vacuum-microwave dried samples (about $200 \mu \mathrm{m}$ ), and they further claimed that French fries pre-dried using the vacuum microwave absorbed less fat than those pre-dried by the convective method. This result was in conformity with our findings.

When the diameter was $0.3-1.2 \mathrm{~mm}$, the TO contents of fried potato samples increased significantly with the increasing of diameters. Moreno and Bouchon ${ }^{8)}$ found that the oil content of fried potato samples pre-dried by freezedrying was greater than that of air pre-dried samples and pore size of air pre-dried samples was much smaller than that of freeze-dried samples ${ }^{19,26)}$. Our results were in agreement with their observation in some sense. Moreira et al. ${ }^{5)}$ claimed that oil uptake was dependent on pore diameters, but they concluded that smaller pores caused higher oil content, which was opposite to our discovery. It may be attributed to the difference of the pore size. The pores in their experiment were capillary pores formed in frying process and small pores resulting in a higher capillary pressure, which was related to the higher oil content. According to the International Union of Pure and Applied Chemistry, pores with radius smaller than 5000 nm may be classified as capillaries, so the pores of 0.3-1.2 $\mathrm{mm}$ in our paper which were also visible after frying, and they were not capillary pores.

TO contents of $0,0.1$ and $0.2 \mathrm{~mm}$ samples remained almost constant after 10 min frying, which was about $48.6 \%$. While there was no significant change in TO contents for fried potato chips with pores of 0.3-1.2 mm diameter after 8 min frying $(p>0.05)$ and their equilibrium TO contents were attained when potato chips were fried for 8 min. The equilibrium TO content of samples with $0.3-0.9$ $\mathrm{mm}$ pore significantly increased with the rising of pore diameter, which were about $6.2-22.5 \%$ higher than that of the control $\left(\right.$ Increasing rate $\left.(\%)=\left(\mathrm{TO}_{\text {pore }}-\mathrm{TO}_{\text {control }}\right) / \mathrm{TO}_{\text {control }}\right)$. Potato slices with different pore diameters could also alter water evaporation behavior, which affected equilibrium TO content and oil absorption during frying. Vauvre et $a l .{ }^{21)} \mathrm{re}-$ ported that an average potato cell diameter was about 200 $\mu \mathrm{m}$, so the bigger the pore, the more damaged the cells. When potato slices were immersed in hot oil, water released selectively through defects and open channels ${ }^{27)}$. As the process progressed, some of this vapor may be trapped 
within the pores, becoming superheated, distorting the pore walls and contributing to product porosity ${ }^{28)}$. According to Fig. 2, as the pore diameter increased, the drying rate increased and evaporation of water was more intense, so more pores, cracks, voids and open channels formed, which contribute to the space available for oil absorption ${ }^{29)}$. It was noticed that there was no significant increase of the equilibrium TO contents of $1.2 \mathrm{~mm}$ sample compared with that of $0.9 \mathrm{~mm}$ sample $(p>0.05)$, so the oil absorption tended to be saturated at $0.9 \mathrm{~mm}$. However, when the pore diameter was $0.3-1.2 \mathrm{~mm}$, TO of samples significantly increased with the increasing of pore diameter, which was probably related to the more pores, cracks, voids and open channels formed during quicker evaporation of water.

\subsection{Oil fractions during frying processing}

\subsubsection{SO}

The result of oil fractions of the potato chips with different pore diameters at the different frying times is depicted in Table 1. SO content dropped for all pore diameters as frying time increased. The content of SO fraction was the lowest among three different fractions, which was about 1.1-2.3\%. Pedreschi et $a l .{ }^{30)}$ also observed the similar phenomenon. Because of the lowest content of SO, it was supposed that the variation of SO fraction contributed little to the changing of oil absorption for the samples with the different pore diameters.

3.3.2 PSO

As shown in Table 1, PSO constituted the highest fraction of TO during the first 6 min frying and declined gradually during whole frying. This result was related to the condensation mechanism of oil absorption. In this time interval, moisture evaporated at a fast rate, steam condensed and the most oil penetrated right after removal of the samples from the oil bath ${ }^{311}$. During the later process of frying, there was no significant difference in PSO contents for all samples and the PSO content kept constant at 8 or $10 \mathrm{~min}$.

During the beginning of frying (2-4 min), the PSO contents increased with the increasing of pore diameter and it was higher than that of the control. At the frying time of 2 min, PSO of sample with $0.9 \mathrm{~mm}$ pore was $36.2 \%$ and it in-

Table 1 SO, PSO and STO contents of fried potato chips with different pore diameters at different frying times.

\begin{tabular}{ccccccll}
\hline \multirow{2}{*}{$\begin{array}{c}\text { Oil } \\
\text { fractions }\end{array}$} & $\begin{array}{c}\text { Diameter } \\
(\mathrm{mm})\end{array}$ & \multicolumn{7}{c}{ Frying time $(\mathrm{min})$} \\
\cline { 2 - 7 } & 0 & $2.1 \pm 0.2 \mathrm{BCa}$ & $1.7 \pm 0.0 \mathrm{ABb}$ & $1.4 \pm 0.2 \mathrm{ABCb}$ & $1.2 \pm 0.0 \mathrm{Ac}$ & $1.1 \pm 0.0 \mathrm{Ad}$ & $1.3 \pm 0.1 \mathrm{ABc}$ \\
& 0.1 & $2.2 \pm 0.1 \mathrm{BCa}$ & $1.8 \pm 0.0 \mathrm{ABb}$ & $1.8 \pm 0.1 \mathrm{Ab}$ & $1.6 \pm 0.1 \mathrm{Bc}$ & $1.4 \pm 0.0 \mathrm{Bd}$ & $1.2 \pm 0.0 \mathrm{Be}$ \\
& 0.2 & $1.8 \pm 0.0 \mathrm{Aab}$ & $1.8 \pm 0.0 \mathrm{Ba}$ & $1.6 \pm 0.1 \mathrm{Ab}$ & $1.4 \pm 0.1 \mathrm{ABc}$ & $1.2 \pm 0.1 \mathrm{ABd}$ & $1.3 \pm 0.0 \mathrm{ABcd}$ \\
SO (\%) & 0.3 & $2.3 \pm 0.1 \mathrm{Ca}$ & $1.8 \pm 0.1 \mathrm{ABb}$ & $1.3 \pm 0.1 \mathrm{BCc}$ & $1.3 \pm 0.1 \mathrm{ABc}$ & $1.1 \pm 0.0 \mathrm{Ad}$ & $1.1 \pm 0.0 \mathrm{Ad}$ \\
& 0.6 & $2.2 \pm 0.0 \mathrm{BCa}$ & $1.7 \pm 0.0 \mathrm{ABb}$ & $1.5 \pm 0.0 \mathrm{Bc}$ & $1.5 \pm 0.2 \mathrm{ABc}$ & $1.3 \pm 0.0 \mathrm{ABc}$ & $1.3 \pm 0.0 \mathrm{Cc}$ \\
& 0.9 & $2.0 \pm 0.1 \mathrm{Ba}$ & $1.6 \pm 0.1 \mathrm{Ab}$ & $1.3 \pm 0.0 \mathrm{Cb}$ & $1.4 \pm 0.2 \mathrm{ABb}$ & $1.3 \pm 0.1 \mathrm{Bb}$ & $1.2 \pm 0.0 \mathrm{Bb}$ \\
& 1.2 & $2.0 \pm 0.0 \mathrm{Ba}$ & $1.9 \pm 0.2 \mathrm{Bab}$ & $1.7 \pm 0.1 \mathrm{Ab}$ & $1.4 \pm 0.1 \mathrm{ABc}$ & $1.4 \pm 0.0 \mathrm{Bc}$ & $1.5 \pm 0.0 \mathrm{Dc}$ \\
& 0 & $31.9 \pm 1.4 \mathrm{ABa}$ & $31.8 \pm 0.6 \mathrm{ABa}$ & $28.7 \pm 1.6 \mathrm{BCa}$ & $25.1 \pm 0.8 \mathrm{BCb}$ & $21.7 \pm 0.1 \mathrm{Ac}$ & $20.4 \pm 1.3 \mathrm{Ac}$ \\
& 0.1 & $32.7 \pm 0.2 \mathrm{Aa}$ & $30.6 \pm 0.9 \mathrm{Aab}$ & $28.6 \pm 1.0 \mathrm{Cb}$ & $23.4 \pm 0.9 \mathrm{ABc}$ & $20.0 \pm 0.7 \mathrm{ABd}$ & $20.5 \pm 0.0 \mathrm{Ad}$ \\
& 0.2 & $32.2 \pm 0.1 \mathrm{Aa}$ & $30.8 \pm 0.1 \mathrm{Aab}$ & $29.2 \pm 0.0 \mathrm{Cb}$ & $22.3 \pm 1.1 \mathrm{Ac}$ & $22.8 \pm 0.8 \mathrm{Bc}$ & $20.4 \pm 0.4 \mathrm{Ad}$ \\
& 0.3 & $32.6 \pm 0.6 \mathrm{Aa}$ & $32.7 \pm 0.2 \mathrm{BCa}$ & $27.7 \pm 0.1 \mathrm{BCb}$ & $23.1 \pm 0.6 \mathrm{ABc}$ & $22.6 \pm 0.5 \mathrm{Bc}$ & $20.7 \pm 1.1 \mathrm{Ad}$ \\
& 0.6 & $34.6 \pm 0.4 \mathrm{Ba}$ & $34.2 \pm 0.1 \mathrm{CDa}$ & $25.9 \pm 0.0 \mathrm{Ab}$ & $24.1 \pm 0.5 \mathrm{ABc}$ & $23.0 \pm 0.7 \mathrm{Bcd}$ & $22.6 \pm 0.0 \mathrm{ABd}$ \\
& 0.9 & $36.2 \pm 0.4 \mathrm{Ca}$ & $34.0 \pm 0.6 \mathrm{CDa}$ & $25.9 \pm 0.7 \mathrm{Ab}$ & $27.1 \pm 0.0 \mathrm{Cb}$ & $22.1 \pm 1.5 \mathrm{ABc}$ & $22.0 \pm 0.2 \mathrm{ABc}$ \\
& 1.2 & $37.0 \pm 0.3 \mathrm{Ca}$ & $34.5 \pm 0.7 \mathrm{Db}$ & $26.6 \pm 0.3 \mathrm{ABc}$ & $26.5 \pm 0.5 \mathrm{Cc}$ & $24.2 \pm 0.1 \mathrm{Bd}$ & $24.0 \pm 0.8 \mathrm{Bd}$ \\
& 0 & $6.4 \pm 1.0 \mathrm{Aa}$ & $7.7 \pm 0.4 \mathrm{Aa}$ & $11.7 \pm 0.8 \mathrm{Bb}$ & $19.0 \pm 1.0 \mathrm{Ac}$ & $25.1 \pm 0.6 \mathrm{Ad}$ & $26.9 \pm 0.8 \mathrm{Ad}$ \\
& 0.1 & $6.4 \pm 0.4 \mathrm{Aa}$ & $8.5 \pm 0.0 \mathrm{Ab}$ & $11.5 \pm 0.3 \mathrm{ABc}$ & $18.6 \pm 0.5 \mathrm{Ad}$ & $27.5 \pm 0.4 \mathrm{ABe}$ & $27.1 \pm 1.2 \mathrm{Ae}$ \\
& 0.2 & $7.5 \pm 0.0 \mathrm{Aa}$ & $8.1 \pm 0.1 \mathrm{Aa}$ & $10.3 \pm 0.0 \mathrm{Aa}$ & $19.5 \pm 1.3 \mathrm{Ab}$ & $24.8 \pm 1.9 \mathrm{Ac}$ & $28.7 \pm 0.8 \mathrm{ABc}$ \\
& 0.3 & $9.2 \pm 0.1 \mathrm{BCa}$ & $10.1 \pm 0.1 \mathrm{Ba}$ & $17.6 \pm 0.6 \mathrm{Cb}$ & $26.5 \pm 0.4 \mathrm{Bc}$ & $29.0 \pm 1.0 \mathrm{BCd}$ & $30.4 \pm 0.4 \mathrm{BCd}$ \\
& 0.6 & $9.9 \pm 0.4 \mathrm{Ca}$ & $14.5 \pm 0.3 \mathrm{Cb}$ & $23.9 \pm 0.1 \mathrm{Dc}$ & $28.8 \pm 0.1 \mathrm{Cd}$ & $31.5 \pm 0.1 \mathrm{CDe}$ & $31.7 \pm 0.1 \mathrm{Ce}$ \\
& 0.9 & $9.1 \pm 0.1 \mathrm{BCa}$ & $16.0 \pm 0.3 \mathrm{Db}$ & $25.8 \pm 0.4 \mathrm{Ec}$ & $30.2 \pm 0.2 \mathrm{CDd}$ & $34.9 \pm 0.8 \mathrm{Ee}$ & $34.9 \pm 0.1 \mathrm{De}$ \\
& 1.2 & $9.0 \pm 0.3 \mathrm{Ba}$ & $16.7 \pm 0.4 \mathrm{~Eb}$ & $27.1 \pm 0.3 \mathrm{Fc}$ & $31.9 \pm 0.6 \mathrm{Dd}$ & $34.0 \pm 0.3 \mathrm{DEe}$ & $34.5 \pm 0.5 \mathrm{De}$ \\
\hline
\end{tabular}

Means with different uppercase letters (A-D) in the same column are significantly different at $p<0.05$. Means with different lowercase letters $(\mathrm{a}-\mathrm{b})$ in the same row are significantly different at $p<0.05$. 


\section{J. Li, T. Zhang and Y. Liu et al.}

creased by $11.0 \%$ as compared to that of $0.3 \mathrm{~mm}$ sample, and increased by $13.5 \%$ as compared to that of the control. At frying time of $4 \mathrm{~min}$, PSO of sample with $0.9 \mathrm{~mm}$ pore was $34.0 \%$ and it increased by $4.0 \%$ as compared to that of $0.3 \mathrm{~mm}$ sample, and increased by $6.9 \%$ as compared to that of the control. At $6 \mathrm{~min}$, the PSO contents were all less than the one of control. At $10 \mathrm{~min}$, there was no significant difference among PSO contents of the samples with all pore diameters $(p>0.05)$. Generally, the PSO contents of samples with different pore diameters had a smaller difference compared with the control. The mean value of variation compared with the control was $7.6 \%$ and PSO affected less on oil absorption during the whole frying process.

\subsubsection{STO}

Table 1 shows that the STO content was independent of the pore diameters $(p>0.05)$ when the diameter was $0,0.1$ and $0.2 \mathrm{~mm}$. There was significant increase in STO content of samples with diameter greater than $0.3 \mathrm{~mm}$ compared with the control $(p<0.05)$. When the diameter was $0.3-1.2$ $\mathrm{mm}$, there was no significant difference of STO contents at 2 min for all samples with different pore diameters and pore diameter had significant effects on STO contents at $4-12 \min (p<0.05)$. Huizenga and Smith ${ }^{17)}$ observed that the effective vapor diffusivity in porous solids increased with the rise of pore size, which was responsible for the above phenomenon. At the beginning of frying ( $2 \mathrm{~min}$ ), moisture evaporates at a very fast rate for all sample with different pore diameters samples, which created an overpressure inside the pores ${ }^{29)}$. So the STO contents were all low at 2 min, which was less than 10\%. The bigger diameters pores didn't generated additional effects on STO content at $2 \mathrm{~min}$. As frying time increased, flow of vapor became weak and the bigger the pore, the weaker the flow. Therefore, STO content significantly increased along with the increasing of frying time during the first $10 \mathrm{~min}$ for all samples with different pore diameters $(p<0.05)$ and it also showed a significant rising with the increasing of pore diameter $(0.3-1.2 \mathrm{~mm})(p<0.05)$. At the later processing of frying, the moisture contents were around $1.5 \%$ for all samples with different pore diameters and the flow of vapor stopped, so this may explain that there was no significant difference in STO contents between the fried samples of $10 \mathrm{~min}$ and $12 \mathrm{~min}(p>0.05)$ and the equilibrium point of STO content was attained at $10 \mathrm{~min}$ for all diameters.

When the pore diameter was 0.3-1.2 mm, it had a significant effect on equilibrium STO content $(p<0.05)$. The equilibrium STO content of $1.2 \mathrm{~mm}$ increased by about $35.2 \%$ as compared to that of control. The maximum STO increment of sample with $1.2 \mathrm{~mm}$ pore appeared at $6 \mathrm{~min}$, about $131.4 \%$. Just as TO content, there was no significant difference in the equilibrium STO contents for both samples of pore diameter of $1.2 \mathrm{~mm}$ and $0.9 \mathrm{~mm}(p>0.05)$. The oil absorption during frying process tended to be satu- rated when the pore diameter was $0.9 \mathrm{~mm}$. In general, the STO content had the similar changing rule and tendency with TO content.

During frying, PSO contents decreased with the increasing of frying time, however STO contents increased with increasing of frying time. During the frying time of 2 to 12 min, PSO of control decreased from $31.9 \%$ to $20.4 \%$, STO increased from $6.4 \%$ to $26.9 \%$; PSO of sample with the 0.3 $\mathrm{mm}$ pore decreased from $32.6 \%$ to $20.7 \%$, and STO increased from $9.2 \%$ to $30.4 \%$; PSO of sample with the 0.9 $\mathrm{mm}$ pore decreased from $36.2 \%$ to $22.0 \%$ and STO increased from $9.1 \%$ to $34.9 \%$.

\subsection{The ratio of increasing of STO content to increasing of TO content}

The ratio of increasing of STO content to increasing of TO content was presented in Fig 4. The ratios of all samples with different pore diameters at every frying time were above $30 \%$. When the potato chips were fried for 4 min, the ratios were all above $70 \%$. The ratios of the potato chips fried for 6 min reached the maximum value, which was more than $100 \%$. When the STO contents of samples with different diameters pores reached the equilibrium point (at $10 \mathrm{~min}$ ), the increment of the corresponding STO contents was around $80 \%$ of the increment of TO contents. So it can be concluded that the STO fraction gave the greatest contribution to the increase of oil absorption during the whole frying process compared with the control. Moreira et al. ${ }^{5)}$ and Moreira and Barrufet ${ }^{32)}$ reported that smaller pores formed during frying resulted in a higher capillary pressure during cooling and then higher final oil content and they concluded that the oil uptake during cooling (PSO) made an explanation for the change of final

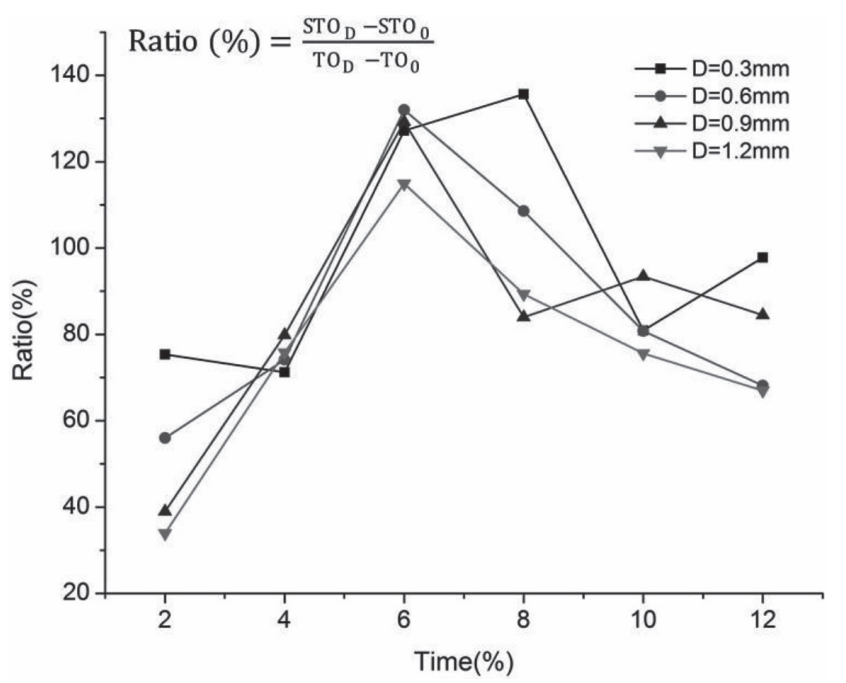

Fig. 4 The ratio of increasing of STO to increasing of TO in fried potato chips with different pore diameters at different frying times. 
oil absorption. The oil absorption in their research was described by capillary flow mechanisms while oil uptake in our paper was attributed to water escape mechanisms that water vapor formed the available space for oil penetration during the frying process and the bigger the pore diameter, the more the oil absorbed. In addition, the oil gradually sucked from the surface to the center of potato chips with the increasing of frying time and the whole areas of potato chips filled with oil at the end of frying, especially the pores and voids. So the STO was primarily responsible for the increment of oil absorption compared with the control.

\section{Conclusions}

In order to accurately investigate the effects of pore diameter on oil absorption of fried potato chips, puncture experiments with different the pore diameter of 0.1-1.2 $\mathrm{mm}$ were carried out in this paper. According to our experimental results when using palm oil, we conclude that the initial pore diameter had no significant effect on the oil absorption compared with the control when it was 0.1 and 0.2 $\mathrm{mm}(p>0.05)$; oil absorption increased significantly with the increasing of pore diameter when it was $0.3-0.9 \mathrm{~mm}(p$ $<0.05)$; oil absorption tended to be saturated at $0.9 \mathrm{~mm}$ pore diameter. When the pore diameter was $0.3-1.2 \mathrm{~mm}$, the increment of STO content was the dominant section for the increase of TO content, so it was STO fraction that gave the greatest contribution to the increasing of oil absorption compared with the control.

\section{Acknowledgements}

The authors acknowledge the financial support of the Special Fund for Grain Research in the Public Interest (201313011-6-4), Agro-scienticfic Research in the Public Interest(201303073-01), China National Natural Science Foundation (31371812, 31571878, 31471617), Natural Science Foundation of Jiangsu Province (BK20131104), and the Fundamental Research Funds for the Central Universities (JUSRP51501), Jiangsu province science and technology Project (SBN2014010290, BN2014058, BM2014051) which has enabled us to carry out this study.

\section{References}

1) Tarmizi, A. H. A.; Niranjan, K. Combination of moderate vacuum frying with high vacuum drainage-relationship between process conditions and oil uptake. Food Bioprocess Tech. 6, 2600-2608(2013).

2) Adedeji, A. A.; Liu, L.; Ngadi, M. O. Microstructural evaluation of deep-fat fried chicken nugget batter coating using confocal laser scanning microscopy. $J$. Food Eng. 102, 49-57(2011).

3) Saguy, I. S.; Dana, D. Integrated approach to deep fat frying: Engineering, nutrition, health and consumer aspects. J. Food Eng. 56, 143-152 (2003).

4) Troncoso, E.; Pedreschi, F. Modeling water loss and oil uptake during vacuum frying of pre-treated potato slices. Lwt-Food Sci. Technol. 42, 1164-1173(2009).

5) Moreira, R. G.; Sun, X. Z.; Chen, Y. H. Factors affecting oil uptake in tortilla chips in deep-fat frying. J. Food Eng. 31, 485-498(1997).

6) Krokida, M. K.; Oreopoulou, V.; Maroulis, Z. B.; Marinos-Kouris, D. Effect of osmotic dedydration pretreatment on quality of french fries. J. Food Eng. 49, 339345 (2001).

7) Zielinska, M.; Blaszczak, W.; Devahastin, S. Effect of superheated steam prefrying treatment on the quality of potato chips. Int. J. Food Sci. Tech. 50, 158-168 (2015).

8) Moreno, M. C.; Bouchon, P. A. different perspective to study the effect of freeze, air, and osmotic drying on oil absorption during potato frying. J. Food Sci. 73, E122-E128(2008).

9) Bouchon, P.; Aguilera, J. M.; Pyle, D. L. Structure oilabsorption relationships during deep-fat frying. $J$. Food Sci. 68, 2711-2716(2003).

10) Bouchon, P.; Pyle, D. L. Studying oil absorption in restructured potato chips. J. Food Sci. 69, E115-E122 (2004).

11) Mariscal, M.; Bouchon, P. Comparison between atmospheric and vacuum frying of apple slices. Food Chem. 107, 1561-1569 (2008).

12) Sobukola, O. P.; Dueik, V.; Bouchon, P. Understanding the effect of vacuum level in structure development and oil absorption in vacuum-fried wheat starch and gluten-based snacks. Food Bioprocess Tech. 6, 20102017 (2013).

13) Kassama, L. S. Pore development in food during deep-fat frying. McGill University (2003).

14) Dullien, F. A. Porous media: Fluid transport and pore structure. Academic press (2012).

15) Pinthus, E. J.; Weinberg, P.; Saguy, I. S. Oil uptake in deep fat frying as affected by porosity. J. Food Sci. 60, 767-769 (1995).

16) Cortes, P.; Badillo, G.; Segura, L.; Bouchon, P. Experimental evidence of water loss and oil uptake during simulated deep-fat frying using glass micromodels. $J$. Food Eng. 140, 19-27 (2014).

17) Huizenga, D. G.; Smith, D. M. Knudesen diffusion in random assemblages of uniform spheres. AIChE J. 32, 1-6 (1986).

18) Karathanos, V. T.; Saravacos, G. D. Porosity and pore size distribution of starch materials. J. Food Eng. 18, 259-280 (1993). 
19) Rahman, M. S. Toward prediction of porosity in foods during drying: A brief review. Drying Technol. 19, 1-13(2001).

20) Farid, M.; Kizilel, R. A new approach to the analysis of heat and mass transfer in drying and frying of food products. Chem. Eng. Process 48, 217-223(2009).

21) Vauvre, J. M. ; Kesteloot, R.; Patsioura, A.; Vitrac, O. Microscopic oil uptake mechanisms in fried products. Eur. J. Lipid Sci. Tech. 116, 741-755(2014).

22) Krokida, M. K.; Oreopoulou, V.; Maroulis, Z. B. Water loss and oil uptake as a function of frying time. $J$. Food Eng. 44, 39-46 (2000).

23) Fan, L. P.; Zhang, M.; Mujumdar, A. Vacuum frying of carrot chips. Drying Technol. 23, 645-656 (2005).

24) Luyten, A.; Pluter, J. J.; van Vliet, T. Crispy/crunchy crusts of cellular solid foods: A literature review with discussion. J. Texture Stud. 35, 445-492(2004).

25) Tajner-Czopek, A.; Figiel, A.; Carbonell-Barrachina, Á. A. Effects of potato strip size and pre-drying method on french fries quality. Eur. Food Res. Technol. 227, 757-766 (2007).

26) Karathanos, V. T.; Kanellopoulos, N. K.; Belessiotis, V. G. Development of porous structure during air drying of agricultural plant products. J. Food Eng. 29, 167183 (1996).

27) Dana, D.; Saguy, I. S. Mechanism of oil uptake during deep-fat frying and the surfactant effect-theory and myth. Adv. Colloid Interface Sci. 128-130, 267-272 (2006).

28) Ziaiifar, A. M.; Achir, N.; Courtois, F.; Trezzani, I.; Trystram, G. Review of mechanisms, conditions, and factors involved in the oil uptake phenomenon during the deep-fat frying process. Int. J. Food Sci. Tech. 43, 1410-1423 (2008).

29) Miri, T.; Bakalis, S.; Bhima, S. D.; Fryer, P. Use of x-ray micro-ct to characterize structure phenomena during frying. IUFoST, DOI: 10.1051/IUFoST:2006002(2006).

30) Pedreschi, F.; Cocio, C.; Moyano, P.; Troncoso, E. Oil distribution in potato slices during frying. J. Food Eng. 87, 200-212(2008).

31) Mellema, M. Mechanism and reduction of fat uptake in deep-fat fried foods. Trends Food Sci. Tech. 14, 364$373(2003)$.

32) Moreira, R. G.; Barrufet, M. A. A new approach to describe oil absorption in fried foods: A simulation study. J. Food Eng. 35, 1-22(1998). 